\title{
EXPLORING THE COPING MECHANISM OF WOMEN EXPERIENCING INTIMATE PARTNER VIOLENCE IN MALAYSIA
}

\author{
Siti Waringin Oon ${ }^{1^{\star}}$, Rashidah Shuib ${ }^{1}$, Siti Hawa $\mathrm{Ali}^{2}$, Noraida Endut ${ }^{1}$, Intan \\ Osman $^{3}$, Sarimah Abdullah ${ }^{4}$ and Puzziawati Abdul Ghani ${ }^{5}$ \\ ${ }^{1}$ Centre for Research on Women and Gender (KANITA), Universiti Sains Malaysia. \\ Email: waringin@usm.my, rashidahshuib@usm.my, noraidaendut@usm.my \\ ${ }^{2}$ School of Health Sciences, Universiti Sains Malaysia \\ Email: hawali@usm.my \\ ${ }^{3}$ Faculty of Business and Information Sciences, UCSI University \\ Email: intanosman@yahoo.com \\ ${ }^{4}$ School of Medical Sciences, Universiti Sains Malaysia \\ Email: sarimah@usm.my \\ ${ }^{5}$ Faculty of Mathematical and Computer Sciences, Universiti Teknologi MARA, Shah Alam \\ Email: puzzi kamel@salam.uitm.edu.my \\ ${ }^{*}$ Corresponding author
}

\begin{abstract}
Intimate partner violence (IPV) is a long standing issue that affects women worldwide. In surviving the IPV, women often need to strategize to stay alive and to seek help to end the violence. It is important to explore their strategies for survival in this type of violent relationship. Such exploration remains uninvestigated especially in Malaysia. To fill in this gap, this study aims to examine the coping mechanism of women who have experienced IPV in Malaysia. A total number of 234 women experiencing IPV were recruited for this study and the respondents were chose from all States in the Peninsular Malaysia. The study involved a household survey using a random sampling of enumeration blocks to collect the data. The data were collected using the instrument of the WHO multi-country study. Prior to being interviewed, each respondent was given an information sheet, explaining the study, their rights to participate and withdraw from the interview, as well as the assurance of confidentiality. Results of the study indicate that about $83 \%$ (194) of the survivors attempted to seek help from individuals outside of their marriages and from the authorities. The majority of respondents informed individuals about their problem, which indicate the important role of family members and friends in providing intervention in IPV. About $16.5 \%$ of respondents reveal their issues to and seek help from the authorities and the majority of these were satisfied with the services they received from the authorities. In conclusion, this study suggests that intervention to IPV cases may be made more effective by understanding women's help-seeking strategies and improving on these strategies.
\end{abstract}

Keywords: Coping mechanism, intimate partner violence, experience, survivors, Malaysia 


\section{INTRODUCTION}

Intimate partner violence or domestic violence come in various forms that range from using nasty words against a partner, shouting at her, kicking her on different parts of the body to threatening her life or actually killing her (Canada Violence Prevention Initiative, 2015). The violence can also be categorized into nine distinct forms such as physical, verbal, emotional, sexual, psychological, spiritual, cultural, financial abuse and neglect (Canada Violence Prevention Initiative, 2015). Women in IPV suffer one or multiple forms of this violence. Intimate partner violence may occur only once, can involve various tactics of subtle manipulation or may occur frequently while escalating over a period of months or years. According to WHO (2013), $30 \%$ of women were attacked by their partners globally. In Malaysia, findings from the prevalence study done by Rashidah et al. (2013) reported that 9 out of 100 women in Malaysia experienced IPV. Although this percentage appears small, when applied to the total population of Malaysia, it can indicate a significant number of cases of IPV in the society, particularly when compared to annual reported cases.

Previous studies had mentioned that intimate partner violence is hidden from society's view because most incidents are under reported (Herzberger, 1996; Frieze and Brown, 1989). Many women remain silent about the experiences. This under-reporting should be tackled by authorities and society urgently because violence can affect the health and well-being of IPV survivors significantly. Impact of IPV on the health and wellbeing of women can be immediate or delayed and can be for a long term that extends even after their relationships to the perpetrators have ended (WHO, 2000; Vic Health, 2004). Therefore, escaping violence become highly crucial for women to ensure their survival and their restored health. Women's ability to survive IPV is influenced by many factors including such as frequency and severity of the violence they experience, the length of their relationships with the perpetrators and the availability of both formal and informal support networks (Waldrop \& Resick, 2004). In addition, according to studies done by Chang et al. (2010) and Randell et al. (2012), another trigger that influences women to seek help is when the women realize that their children are in danger. Due to the aforementioned reasons, women have adopted various strategies to survive including fighting back, leaving the partner/home permanently or temporarily and seeking help from institutions or family members and friends. Many studies have shown that a woman's informal support networks such as family members and friends are where she seeks help the most ( $\mathrm{Tg}$ Nurfadzilah et al., 2015; Meyer,2010; Bruschi, Paula, \& Bordin, 2006; Garcia Moreno et al., 2005). However, there is a scarcity of study that looks at the coping mechanisms of women in getting formal and informal support from individuals or authorities. This paper seeks to investigate surviving IPV amongst women by looking at their coping mechanisms to formal (the authorities) and informal (families and friends) support.

\section{METHODOLOGY}

\subsection{Sampling information and instrument}

This paper is based on a prevalence study of IPV in Malaysia, using the World Health Organisation (WHO)'s instrument. The study was a prevalence study of IPV in the Peninsular Malaysia. Malaysia has 14 States: 12 in the Peninsular or West Malaysia (including the Federal Territories) and two in the East Malaysia. These latter two States (Sabah and Sarawak) were not covered by the prevalence study due to time, accessibility and financial constraints. The study covers both the rural and urban areas of the 12 States and Federal Territories. The total numbers of female respondents recruited in this study was 3391 and only 234 women experienced intimate partner violence. The respondents were selected randomly from the population data set provided by the Statistics Department based on a set of inclusion criteria. The respondents were chosen based on these criteria: (a) Female, (b) 18 to 49 years of age, (c) Malaysian citizen or has permanent resident status, (d) Married, divorced, widowed or in an intimate relationship for more than a year. Based on these criteria, 3391 female respondents were interviewed using a questionnaire that was adapted from instrument of the WHO Multi-Country study (WHO, Version 10, 2010). Only 234 women were found to have experienced IPV and this paper is based on the responses of these women.

\subsection{Ethical consideration}

In order to ensure the safety of respondents and the confidentiality of their responses, only one woman per household was selected. Each respondent was interviewed on a one-to-one basis in a private space since the instrument contained questions that might be deemed sensitive by the respondents. Prior to being interviewed, each respondent was given an information sheet, explaining the study, their rights to participate and withdraw from the interview, as well as the assurance of confidentiality.

\subsection{Data analysis}

Data were entered into Epidata and cleaned. Thereafter, data were transferred and analyzed using SPSS 
Version 18 software.

\section{RESULTS}

Table 1: Respondents' Socio-demographic Profile

\begin{tabular}{|l|l|l|}
\hline \multicolumn{1}{|c|}{ Profile } & Categories & $\begin{array}{l}\text { Percentage } \\
(\%)\end{array}$ \\
\hline Location & Urban & 59.0 \\
& Rural & 41.0 \\
\hline Age group & & 7.7 \\
(years) & $18-24$ & 28.7 \\
& $25-33$ & 33.3 \\
Marital status & $34-42$ & 30.3 \\
& $43-49$ & 73.5 \\
& Currently married & 0.4 \\
& Living with man, not married & 0.4 \\
& Partner, living apart & 25.7 \\
\hline Level of & Not currently married/No partner & 2.6 \\
education & No education & 12.0 \\
& Primary & 70.1 \\
No. of people & Secondary & 15.3 \\
in the & Tertiary & 20.9 \\
household & $1-3$ & 59.0 \\
& $4-6$ & 16.2 \\
\hline
\end{tabular}

Table 1 presents the distribution of the respondents based on location (urban/rural), level of education, age groups, marital status and number of the households. The percentage of respondents from the urban area is slightly higher, which accounts for more than half of the total respondents surveyed (59\%). The majority of the respondents were in the age group of 34-42 years (33.1\%), followed by age group of $43-49$ years (30.3\%), age group of $25-33$ years (28.7\%) and the least was age group of $18-24$ years $(7.7 \%)$. In terms of marital status, the majority of the respondents surveyed were currently married (73.5\%), followed by not currently married or no partner (25.7\%) and living with a man and not married and having a partner but living apart respectively having a similar percentage $(0.4 \%)$. Most of the respondents have secondary education which accounts for more than half of the total respondents surveyed $(70.1 \%)$. The lowest percentage of respondents was with no education $2.6 \%$. Most of the households $(59.0 \%)$ had between four to six family members, followed by one to three family members $(20.9 \%)$, seven to nine family members $(16.2 \%)$ and 10 to 12 family members (3.9\%).

\section{Informing about partner's behavior}

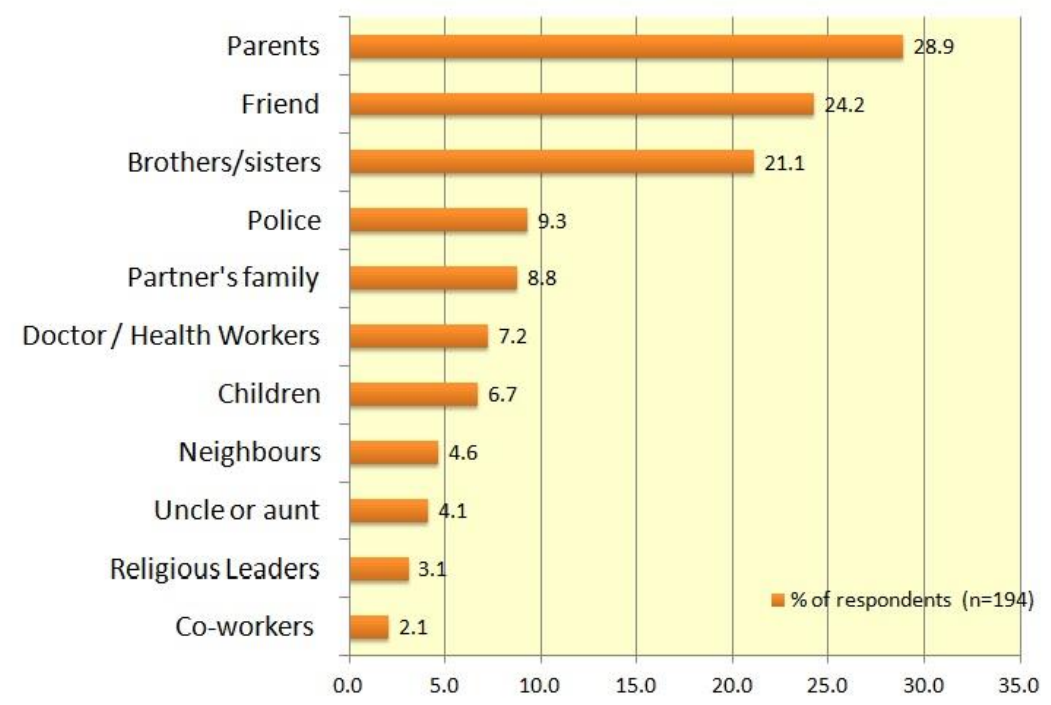

Fig 1: Percentage of the survivors who inform someone about their partner's behaviour 
One hundred and ninety four (82.9\%) respondents reported that they had informed about their partners' behaviour to someone. Figure 1 shows that most of the survivors informed about their partners' behaviour to their parents $(28.9 \%)$, friends $(24.2 \%)$, and brothers and sisters $(21.1 \%)$. Less than $10 \%$ had informed police, their partners' family members, health workers, their children, neighbours, uncles or aunts, religious leaders or co-workers. From the findings, it shows that women preferred to share information about their IPV experiences with individuals who are close to them compared to the authorities (police, health workers, religious leaders). They also did not share their problems with individuals who may not be too close with them (partners' family members, uncles/ aunts, co-workers). Women may not have shared their experiences of violence with their children because the children may be too young or vulnerable or to protect the children from negative knowledge.

\section{Seeking assistance from the authorities and the level of satisfaction}

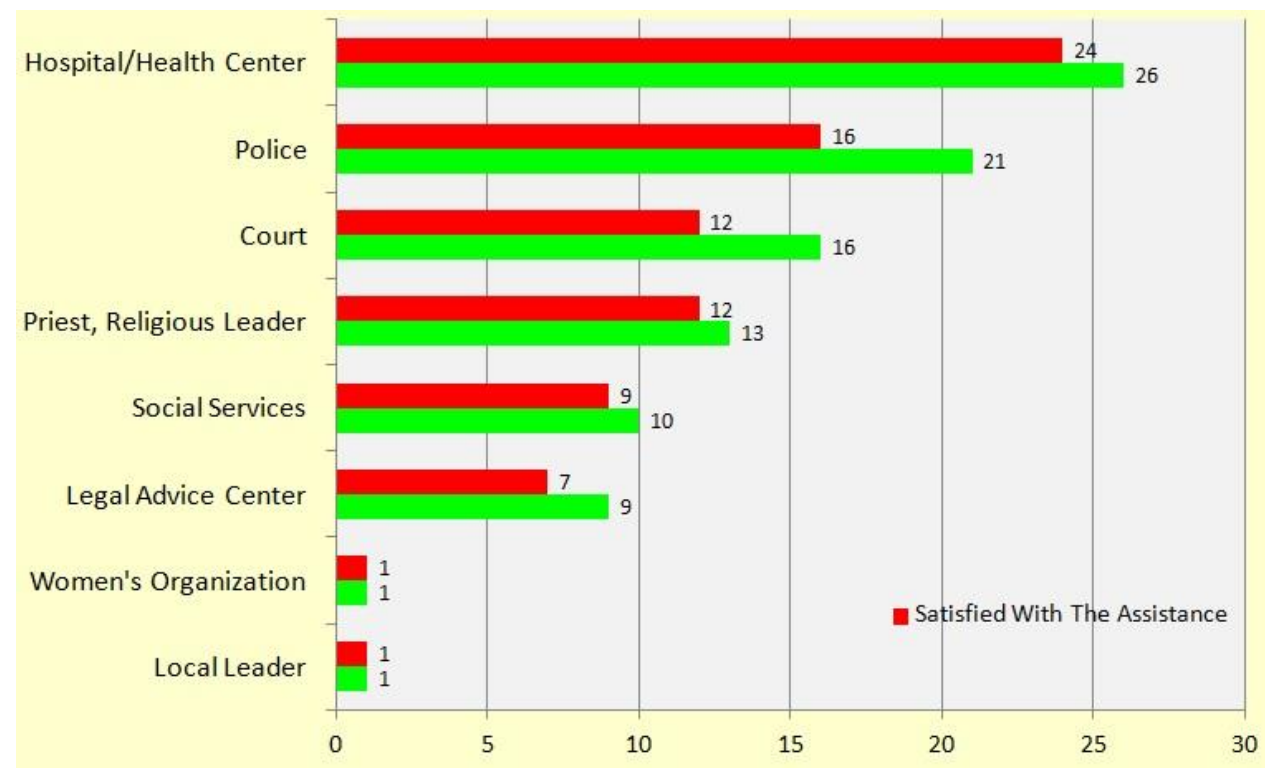

Fig 2: Numbers of survivors seeking assistance from the authorities and the level of satisfaction

Most of the women who have sought help from the authorities do so at the hospital. Majority of the women (92.3\%) who had sought assistance from hospitals felt satisfied with the services given to them. About $76 \%$ of the survivors who had sought assistance from the police were satisfied with police intervention. Sixteen survivors were seeking assistance from the court and $75 \%$ were satisfied with the service. Figure 2 also shows that more than $75 \%$ satisfied with the religious leader, court, social services, legal advice centres, women's organisations and local leaders.

\section{DISCUSSION AND CONCLUSION}

The findings of the study on which this paper is based indicate that women seek help both from individuals and authorities as part of their coping mechanisms. Women tend to share information about their partners' behavior with individuals who are close with them. This findings are supported by a previous study mentioned earlier in this paper that women will share intimate or family problems with someone they know and they primarily turned to informal sources of support such as family and friends, rather than formal support systems (Tg. NurFadzilah et al.(2015). In contrast, majority of the women remain silent and had not told anyone about their violence experience because they thought it was a private matter (Garcia-Moreno et al., 2005; Jayasuria, Wijewardena, \& Axemo, 2011).

Study found that women are likely to seek help from the authorities. This is due to the fact that they feel safe and protected once they got assistance from the authorities especially from the health centre and police department. Besides, this also can be possible that they seek for medical assistance after the injury of violent event and also they had to report to the police about the cases. Findings from other studies also reported similar situations (Black, 2011; Marinheiro et al., 2006), which show that healthcare services were seen as a potential entry point for identifying women in abusive relationships.

In terms of their level of satisfaction with the provision of the related services, majority of women feel satisfied and coping well with the services given to them. It can be presumed that they think the authorities involved were supportive and they can rely on them. 
In conclusion, women who were experienced intimate partner violence were assertive in seeking help for their survival in abusive relationship. They need a supportive environment from the individuals and authorities as part of their coping mechanisms in facing this problem. Therefore, it is important for the individual and authorities to play their roles extensively in helping these women to go through their lives. To support their health seeking initiatives, there is a need to formulate a better strategy to further provide women assistance including women friendly channels for them to encounter problems related to intimate partner violence.

\section{ACKNOWLEDGEMENT}

The author would like to acknowledge the research project funded by Universiti Sains Malaysia under the Research University (RU) Grant, Project No: 1001/PKANITA/650561 for the publication of this paper.

\section{REFERENCES}

Black, M.C. (2011). Intimate partner violence and adverse health consequences: Implications for clinicians. American Journal of Lifestyle Medicine, 5, 428-439. doi:10.1177/1559827611410265

Bruschi, A.,Paula, C.S.de,\& Bordin,I.A.S. (2006).Lifetime prevalenceand help seekingbehavior inphysical marital violence. Rev Saude Publica, 40(2), 256-264. doi:10.1590/S0034-89102006000200011

Canada Violence Prevention Initiative, (2015).

Chang, J.C., Dado, D., Hawker, L., Cluss, P.A., Buranosky, R., Slagel, L., Scholle, S.H. (2010). Understanding turning points in intimate partner violence: Factors and circumstances leading women victims toward change. Journal of Women's Health, 19(2), 251-259. doi:10.1089/jwh.2009.1568

Frieze, I.H., \& Browne, A. (1989) Violence in marriage. In L.E. Ohlin \& M. H. Tonry (Eds.) Family violence. Chicago, IL: University of Chicago Press.

Garcia-Moreno,C.,Jansen,H.A.F.M.,Ellsberg,M.,Heise,L.,\&Watts,C.(2005).WHOmulti-countrystudy on women's health and domestic violence against women: Initial results on prevalence, health outcomes and women's response. World Health Organization.

Herzberger, S.D. (1996) Violence within the family: Social psychological perspectives. Boulder, CO: Westview Press.

Jayasuria, V., Wijewardena, K., \& Axemo, P. (2011). Intimate partner violence against women in the capital province of Sri Lanka: Prevalence, risk factors and help seeking. Violence Against Women, 17(8), 1086- 1102. doi:10.1177/1077801211417151

Marinheiro, A.L.V., Vieira, E.M., \& Souza, L. de. (2006). Prevalence of violence against women users of health care services. Rev Saude Publica, 40(4), 604-610. doi:10.1590/S0034-89102006000500008

Meyer, S. (2010). Responding to intimate partner violence victimisation: Effective options for help-seeking. Trends \& Issues in Crime and Criminal Justice, (389), 1-6.

Rashidah, S., Noraida, E., Siti Hawa, A., Intan,O., Sarimah, A., Siti Waringin,O. (2014). Domestic Violence and Women's Well-being in Malaysia: Issues and Challenges Conducting a National Study Using the WHO Multi-country Questionnaire on Women's Health and Domestic Violence against Women. Procedia - Social and Behavioral Sciences, 91, pp 475-488

Randell, K.A., Bledsoe, L.K., Shroff, P.L., \& Pierce, M.C. (2012). Mothers' motivation for intimate partner violence help-seeking. Journal of Family Violence, 27, 55 -62. doi:10.1007/s10896-011-9401-5

Tg.NurFadzilah,T.H., Siti Hawa, A., \& Halim, S. (2015). Patterns of help-seeking among women experiencing intimate partner violence in Malaysia. Asian Journal of Women's Studies, 21(1),pp 6172, http://dx.doi.org/10.1080/12259276.2015.1029226

Vic Health, (2004). Preventing violence against women.

World Health Organization, (2000). World Health Report 2000- Health Systems: Improving Performance.

World Health Organization, (2013). Global and regional estimates of violence against women: prevalence and health effects of intimate partner violence and non-partner sexual violence. 